\title{
The bivariate GARCH approach to investigating the relation between stock returns, trading volume, and return volatility
}

\author{
Wen-I Chuang ${ }^{\mathrm{a}}$, Hsiang-His Liu ${ }^{\mathrm{b}}$, and Rauli Susmel ${ }^{\mathrm{c}}$
}

\begin{abstract}
We use a bivariate GJR-GARCH model to investigate simultaneously the contemporaneous and causal relations between trading volume and stock returns and the causal relation between trading volume and return volatility in a one-step estimation procedure, which leads to the more efficient estimates and is more consistent with finance theory. We apply our approach to ten Asian stock markets: Hong Kong, Japan, Korea, Singapore, Taiwan, China, Indonesia, Malaysia, the Philippines, and Thailand. Our major findings are as follows. First, the contemporaneous relation between stock returns and trading volume and the causal relation from stock returns and trading volume are significant and robust across all sample stock markets. Second, there is a positive bi-directional causality between stock returns and trading volume in Taiwan and China and that between trading volume and return volatility in Japan, Korea, Singapore, and Taiwan. Third, there exists a positive contemporaneous relation between trading volume and return volatility in Hong Kong, Korea, Singapore, China, Indonesia, and Thailand, but a negative one in Japan and Taiwan. Fourth, we find a significant asymmetric effect on return and volume volatilities in all sample countries and in Korea and Thailand, respectively.
\end{abstract}

JEL classifications: C32, G12

Key words: Stock returns; Trading volume; Return volatility; Contemporaneous and causal relations; GJR-GARCH

February 2011

\footnotetext{
${ }^{a}$ Corresponding author. Department of Finance, National Taiwan University, No. 1, Section 4, Roosevelt Road, Taipei 10617, Taiwan; tel.: 886-2-3366-9578; fax: 86-2-2366-0764; e-mail: wichuang@ management.ntu.edu.tw b Graduate Institute of International Business, National Taipei University, No. 151, University Road, New Taipei City 23741, Taiwan; tel.: 886-2-2673-6270; fax: 886-2-2673-6271; e-mail: hsiang@ mail.ntpu.edu.tw ${ }^{c}$ Department of Finance, University of Houston, Houston, TX 77204-6282, USA; tel.: 713-743-4763; e-mail: rsusmel@uh.edu
} 


\title{
The bivariate GARCH approach to investigating the relation between stock returns, trading volume, and return volatility
}

\begin{abstract}
We use a bivariate GJR-GARCH model to investigate simultaneously the contemporaneous and causal relations between trading volume and stock returns and the causal relation between trading volume and return volatility in a one-step estimation procedure, which leads to the more efficient estimates and is more consistent with finance theory. We apply our approach to ten Asian stock markets: Hong Kong, Japan, Korea, Singapore, Taiwan, China, Indonesia, Malaysia, the Philippines, and Thailand. Our major findings are as follows. First, the contemporaneous relation between stock returns and trading volume and the causal relation from stock returns and trading volume are significant and robust across all sample stock markets. Second, there is a positive bi-directional causality between stock returns and trading volume in Taiwan and China and that between trading volume and return volatility in Japan, Korea, Singapore, and Taiwan. Third, there exists a positive contemporaneous relation between trading volume and return volatility in Hong Kong, Korea, Singapore, China, Indonesia, and Thailand, but a negative one in Japan and Taiwan. Fourth, we find a significant asymmetric effect on return and volume volatilities in all sample countries and in Korea and Thailand, respectively.
\end{abstract}

JEL classifications: C32, G12

Key words: Stock returns; Trading volume; Return volatility; Contemporaneous and causal relations; GJR-GARCH

February 2011 


\section{Introduction}

From a theoretical and practical standpoint, stock returns, trading volume, and return volatility are jointly and simultaneously determined by the same market dynamics, and are inextricably linked. Prior empirical studies, however, have seldom analyzed stock returns, return volatility and trading volume as a joint system. A partial estimation of the system can hide the true dynamics and lead to inefficient and potentially biased estimations. Many studies have relied on a two-step procedure to avoid the joint estimation of the system. This two-step process may suffer from a generated regressor problem -see Pagan (1984). ${ }^{1}$ A related empirical issue in the prior literature regards the dynamics of trading volume. Trading volume may also exhibit a time varying variance as stock returns. Consequently, the usual OLS estimates of trading volume may be inefficient. ${ }^{2}$

In this paper, we use a bivariate system of equations to estimate the dynamic behavior of stock returns and trading volume. To this end, we specify the conditional mean equations of stock returns and trading volume as a Vector Autoregression (VAR), which allows us to examine the causal relation between stock returns and trading volume. The contemporaneous relation between these two variables is gauged through the conditional contemporaneous correlation coefficient of the model. To introduce into our VAR model return volatility dynamics, we use a bivariate GARCH model, and thus, we incorporate trading volume-return volatility interrelations into the system. The lagged squared residuals of stock returns, endogenously generated from the model, are incorporated into the conditional mean equation of trading volume to measure the causal relation from return volatility to trading volume. Lagged trading volume is added into the conditional variance equation of stock returns to measure the causal relation from trading volume to return volatility.

\footnotetext{
${ }^{1}$ In the typical two-step estimation procedure, return volatility is estimated from a GARCH-type model in the first-step. Then, the contemporaneous and causal relations between trading volume and return volatility are examined in the second-step -see, for example, Darrat, Rahman, and Zhong (2003).

2 It can also lead to biases. For example, Koutmos (1996) find that failure to account for conditional heteroskedasticity leads to upward biased correlation estimates.
} 
Our model specification has three advantages. First, and most importantly, it investigates simultaneously these relations in a one-step estimation procedure, leading to the more efficient estimates. In addition, the simultaneous estimation is more consistent with finance theory, where stock returns, trading volume, and return volatility are jointly and simultaneously determined by the same market dynamics. Second, our GARCH formulation allows us to examine asymmetric effects of positive and negative innovations on both return and volume volatilities. ${ }^{3}$ Third, the more precise measures of the causal relations help investors to predict future stock market movements and the degree of risk and liquidity to develop their trading strategies and firms to make decisions about their corporate strategies. ${ }^{4}$ For example, a better forecast of market liquidity can be obtained conditioning on information embedded in stock returns and return volatility, instead of conditioning on only either one.

We apply our model to ten Asian stock markets: Hong Kong, Japan, Korea, Singapore, Taiwan, China, Indonesia, Malaysia, the Philippines, and Thailand. ${ }^{5}$ We choose these markets for two reasons. First, Griffin, Nardari, and Stulz (2007) argue that the return- and volatility-volume relations should be stronger in less efficient markets such as emerging markets, where presumably information is incorporated in price more sluggishly. With the exception of the first five stock markets, which we use as a benchmark, the Asian stock markets have been widely recognized as emerging markets in the literature -see Richards

\footnotetext{
${ }^{3}$ One constraint of our model is that it cannot measure the contemporaneous relation between trading volume and return volatility. This problem would be solved by introducing concurrent trading volume into the conditional mean equation of stock returns. However, as pointed out by Karpoff (1987) and Lamoureux and Lastrapes (1990), this approach creates a simultaneity problem if trading volume is not exogenous, and distort all relations we want to investigate. To avoid this problem, we do not consider this model specification.

4 For example, Baker and Wurgler (2002) show that firms tend to issue equity when their market valuations are high and repurchase shares when low. Pástor and Veronesi (2005) show that initial public offering (IPO) waves tend to be preceded by high market returns.

5 We also consider including India and Vietnam in our sample and, however, we find that the data on their trading volume are not available from the Datastream database.
} 
(2005) and Edison and Warnock (2008). ${ }^{6}$ Second, most empirical studies have focused on the U.S. stock markets, but relatively little work has been conducted on the Asian stock markets. Our study attempts to remedy this situation.

Our major findings are as follows. First, we find that the contemporaneous relation between stock returns and trading volume and the causal relation between lagged stock returns and current trading volume are statistically significant and robust across all sample stock markets. Second, we find a positive bi-directional causality between stock returns and trading volume only in Taiwan and China. A positive bi-directional causality between trading volume and return volatility is found in Japan, Korea, Singapore, and Taiwan. Third, we find a positive contemporaneous relation between trading volume and return volatility in Hong Kong, Korea, Singapore, China, Indonesia, and Thailand, but a negative one in Japan and Taiwan. Fourth, we find a significant asymmetric effect on stock return volatility in all markets and on volume volatility only in Korea and Thailand.

The remainder of the article is organized as follows. Section 2 provides a brief overview of the literature on the contemporaneous and causal relations between stock returns and trading volume and between trading volume and return volatility. Section 3 introduces the data, describes the method to filter trading volume series to achieve stationarity, and reports some important descriptive statistics on the data. Section 4 discusses our model specification. Section 5 presents and discusses the empirical results. Section 6 concludes the paper.

\section{Literature review}

Ghysels, Gourieá, and Jasiak (2000) briefly summarize stylized facts concerning the price-volume relationship documented in the literature. Four of these stylized facts are related to our study: (1) expected returns depend on traded volumes, though the expected negative

\footnotetext{
${ }^{6}$ According World Bank classifications, Hong Kong, Japan, Korea, Singapore, and Taiwan are classified as developed markets and the other countries of our sample are classified as developing markets.
} 
coefficient of a contemporaneous regression seems to depend on the presence and type of conditioning variables; (2) the contemporaneous relationship between return volatility and trading volume is positive and significant; (3) there is a highly non-linear relationship between prices and volume; and (4) conditioning variables may substantially weaken the linear volatility-volume relationship. We re-examine these stylized facts, emphasizing dynamic aspects.

\subsection{Contemporaneous relation between returns and volume}

The contemporaneous relationship between returns (or price changes) and volume in both equity and bond markets is well studied in the existing literature. A negative relationship between expected -i.e., ex ante- returns and trading volume is usually interpreted as the result of the existence of a liquidity risk premium -see Amihud, Mendelson, and Pedersen (2005). A positive return-volume correlation can also be explained using the models of Epps (1975), Copeland (1976), Jennings, Starks, and Fellingham (1981), and Karpoff (1988), among others. The majority of papers find a positive relationship, as reported by, for example, Epps (1975), Harris (1987), Richardson, Sefcik, and Thompson (1986), and Jain and Joh (1988). But Karpoff (1988) and Kocagil and Shachmurove (1998) find no evidence for a positive relation in futures markets.

\subsection{Causal relation between returns and volume}

Many theoretical works have been devoted to explaining the causal relation between returns and volume. Campbell, Grossman, and Wang (1993), Wang (1994), and Blume, Easley, and O'Hara (1994), among other, propose theoretical models predicting that trading volume has relevant information regarding future stock returns. On the other hand, a positive correlation between lagged stock returns and current trading volume can be derived from 
behavioral finance models -see Shefrin and Statman (1985) and Gervais and Odean (2001). These different theoretical views can be reconciled to a certain degree with a positive-feedback trading model -see De Long, Shleifer, Summers, and Waldmann (1990).

Given the different theoretical conclusions regarding the dynamic relation between volume and stock returns, it is not surprising that the empirical literature finds the mixed results regarding this dynamic relation. Some empirical studies find the ability of volume to predict returns, while others find an opposite result. For example, Lee and Swaminathan (2000) and Gervais, Kaniel, and Mingelgrin (2001) find that past trading volume contains valuable information about future stock returns. On the other hand, Griffin et al. (2007), for example, find that the observation that high market-wide returns are followed by high market-wide volume is a global phenomenon. Moreover, Hiemstra and Jones (1994) and Malliaris and Urrutia (1998), for example, document a lead-lag relation between returns and volume in both directions in stock and futures markets -i.e., a feedback relation.

\subsection{Contemporaneous relation between volume and volatility}

Considered a stylized fact by Ghysels et al. (2000), the positive contemporaneous relation between volume and volatility is well documented in the literature. Karpoff (1987) surveys the early empirical studies documenting a significant positive correlation between trading volume and return volatility (or absolute price changes) in both the equity and futures markets. Using a more modern dynamic framework, Lamoureux and Lastrapes (1990) find that there is a positive contemporaneous relation between trading volume and the conditional volatility in U.S. stock returns -see also Gerlach, Chen, Lin, and Huang (2006). A dissenting view is presented by Darrant, Rahman, and Zhong (2003), who find that the vast majority of the DJIA stocks show no contemporaneous correlation between volume and volatility. 
In the theoretical literature, there is also a consensus for a positive contemporaneous volume-volatility relation. This is the conclusion found by the mixture-of-distributions hypothesis -see, Clark (1973); Epps and Epps (1976); and Tauchen and Pitts (1983)-, the differences-of-opinion models -see Harris and Raviv (1993), Shalen (1993), and Kandel and Pearson (1995)-, and the heterogeneous-asymmetric information models -see Campbell et al. (1993) and Wang (1994).

\subsection{Causal relation between volume and volatility}

A dynamic volume-volatility relation can be explained on the ground of the sequential information arrival models proposed by Copeland (1976), Jennings et al. (1981), and Smirlock and Starks (1985). The empirical literature finds a significant linkage between volume and volatility (or absolute price changes). Lamourex and Lastrapes (1991) show that information contained in trading volume improves the prediction of return volatility. Smirlock and Starks (1988) find that there is a significant causal relation between volume and absolute price changes at the firm level. Using 5-minute intraday data for 30 DJIA stocks, Darrat et al. (2003) find significant evidence of a causal volume-volatility relation.

\section{Data}

\subsection{Data and detrending trading volume}

We use daily market price index and trading volume for the ten Asian stock markets: Hong Kong, Japan, Korea, Singapore, Taiwan, China, Indonesia, Malaysia, the Philippines, and Thailand. The data are extracted from the Datastream database. To avoid the potential problem arising from the structural changes after the Asian financial crisis in the second half

of 1997, the sample period starts from 1998. Specifically, the data cover the sample period from January 1, 1998 to December 31, 2007. The stock market indices for the ten Asian stock 
markets are the Hang Seng Index (HSI) for Hong Kong, the Tokyo Stock Exchange Price Index (TOPIX) for Japan, the Korea Stock Exchange Composite Index (KOSPI) for Korea, the Straits Times Index (STI) for Singapore, the Taiwan Weighted Index (TWI) for Taiwan, the Shanghai Composite Index (SSEC) for China, the Jakarta Composite Index (JKSE) for Indonesia, the Kuala Lumpur Composite Index (KLCI) for Malaysia, the Philippines Stock Exchange Composite Index (PSE) for the Philippines, and the Stock Exchange of Thailand Index (SET) for Thailand. Our sample does not include the dates when trading volume is not available from the Datastream database, and consequently the series of index prices and trading volume are matched for each index. To relate our results to Griffin et al. (2007), we separate our sample into high-income nations -i.e., developed economies- and developing nations -i.e., developing economies- according World Bank classifications based on gross national income (GNI) per capita in 2002 and 2003, the midpoint of our sample period. Specifically, Hong Kong, Japan, Korea, Singapore, and Taiwan are classified as developed economies and the other countries of our sample are classified as developing economies.

We calculate daily close-to-close log returns, which we denote by $R_{t}$. Following Lo and Wang (2000), the log of the total number of shares traded in a trading day is defined as a measure of raw (or undetrended) trading volume, which we denote by $R V_{t}$. Prior empirical studies find significant evidence of both linear and quadratic time trends in the trading volume series and consequently detrend it to achieve stationarity. See, for example, Gallant, Rossi, and Tauchen (1992) and Lo and Wang (2000). We test trend stationarity in raw trading volume by regressing it on a deterministic function of the linear time trend term and on that of the linear and quadratic time trend terms. If the linear and/or the quadratic time trends are significant in the regression, we use the regression's residuals as our measure of (detrended) 
trading volume. ${ }^{7}$ For expositional simplicity, we hereafter refer to detrended trading volume as trading volume or volume, denoted by $V_{t}$.

Panels A and B of Table 1 reports the summary statistics on stock returns and detrended trading volume. Specifically, Panels A and B of Table 1 report the number of observations, sample mean, standard deviation, skewness, excess kurtosis, the $D$-statistic of the Kolmogorov-Smirnov test for normality, the first-order autocorrelation coefficient, $\rho_{1}$, the sum of the first 5 autocorrelations, $S_{5}$, and the LM test for ARCH effects with 10 lags, $\mathrm{ARCH}(10)$, for stock returns and detrended trading volume, respectively.

As expected, Panel A of Table 1 shows that developed markets, on average, have lower mean returns and volatility than developing markets in our sample. The return-to-volatility ratio is 0.017 in developed economies and 0.029 in emerging economies. Stock returns tend to have significant skewness, and excess kurtosis. As a result, normality is rejected in all markets at the $1 \%$ significance level, using the Kolmogorov-Smirnov test. Stock returns show small autocorrelations, though, autocorrelations are, on average, stronger in emerging economies than in developed economies; the average sum of the first 5 autocorrelations is 0.021 in developed economies and 0.096 in emerging economies. The LM-ARCH tests, $\mathrm{ARCH}(10)$ statistic, indicate that squared returns strongly depend upon their past values in all values.

Panel B of Table 1 reports the summary statistics for detrended trading volume. As expected, given that detrended trading volume is just the residuals from a regression, the mean of detrended trading volume for all markets has a zero mean. Comparing the standard deviation of detrended trading volume with that of stock returns, detrended trading volume

\footnotetext{
7 The results of the regressions show that both the linear and quadratic time trends are significant in all sample countries, with two exceptions of Japan and Indonesia. Specifically, the quadratic time trend and the linear time trend are not significant for Japan and Indonesia, respectively. Consequently, we use the residuals from a linear time trend regression as detrended volume for Japan. For all the other series, we use the residuals from a linear trend and quadratic time trend regression for all the other markets. To conserve space, we do not tabulate these results, but they are available from the authors upon request.
} 
has a lower volatility relative to stock returns for all sample stock markets. Detrended trading volume has, on average, a lower volatility in developed countries than in emerging countries (0.458 vs. 0.699). Detrended trading volume tends to show significant skewness and exhibits significant excess kurtosis. With the exception of Hong Kong, the Kolmogorov-Smirnov $D$-statistic rejects the normality for detrened trading volume in all markets. Compared to stock returns, detrended trading volume shows substantially higher autocorrelations in all markets. That is, detrended trading volume is much more persistent. Again, detrended trading volume tends to be more autocorrelated in emerging countries than in developed countries. The LM-ARCH tests are statistically significant at the $1 \%$ level for detrended trading volume for all markets. This indicates that a time-varying second moment is also present in the detrended trading volume series. Taken together, the results from the LM-ARCH tests suggest that we need to specify a proper GARCH-type specification to capture the dependence structures that exist in the first and second moment sequences of stock returns and detrended trading volume. ${ }^{8}$

\section{Methodology}

\subsection{Conditional mean equations}

To investigate the causal relation between stock returns and trading volume and that between current trading volume and lagged return volatility, we model the conditional mean equations of the bivariate model as follows:

$$
R_{t}=\alpha_{R, 0}+\sum_{a=1}^{A} \beta_{R, a} R_{t-a}+\sum_{b=1}^{B} \gamma_{R, b} V_{t-b}+\varepsilon_{R, t},
$$

\footnotetext{
${ }^{8}$ We also test for unit roots on both series of stock returns and detrended trading volume, using the Augmented Dickey-Fuller (ADF) (1979) test and the Phillip-Perron (PP) (1988) test. The test results show that the null hypothesis of a unit root is strongly rejected at conventional significance levels for stock returns and detrended trading volume of all sample stock indices.
} 


$$
V_{t}=\alpha_{V, 0}+\sum_{c=1}^{C} \beta_{V, c} R_{t-c}+\sum_{d=1}^{D} \gamma_{V, d} V_{t-d}+\sum_{e=1}^{E} \varphi_{V, e} \varepsilon_{R, t-e}^{2}+\varepsilon_{V, t}
$$

where $R_{t}$ is the stock return at time $t$ and $V_{t}$ is the trading volume at time $t$. The lag length in equations (1) and (2) is chosen according to the Akaike Information Criterion (AIC).

Equation (2) incorporates lagged squared errors from the mean return equation. We use these lagged squared errors $\varepsilon_{R}^{2}$ as a measure of volatility. In the spirit of Lamoreux and Lastrapes (1991) and Jones, Kaul and Lipson (1994), this structure allows us to investigate whether lagged return volatility causes trading volume. ${ }^{9}$ Although the specification of the conditional mean equations (1) and (2) is not a standard form of the VAR representation with the identical right-hand side independent variables, the rationale of testing the causal relations is the same as that of the Granger causality tests. For example, in equation (1) the $\gamma_{R, b}$ coefficients measure the causal relation between current stock returns and lagged trading volume. The rejection of the null hypothesis that trading volume does not Granger-cause stock returns (i.e., $\gamma_{R, b}=0$ for all $b$ ) indicates a causality running from trading volume to stock returns. Following Chordia and Swaminathan (2000), we also examine whether the sum of the $\gamma_{R, b}$ coefficients in equation (1) is greater than zero. Therefore, we test not only for Granger causality but also for the sign (or net effect) of Granger causality. In equation (2), the causal relation between current trading volume and lagged stock returns and that between current trading volume and lagged return volatility are tested analogously.

\subsection{Conditional variance-covariance model}

To model the dynamics of the second moments of stock returns and trading volume and

\footnotetext{
9 There is no clear theoretical grounds to incorporate lagged $\varepsilon_{V}^{2}$ into equation (1). However, we explored this possibility by estimating the causal relation between lagged $\varepsilon_{V}^{2}$ and $R_{t}$ and the contemporaneous relation between $\varepsilon_{V}^{2}$ and $R_{t}$. We found that there is a significant positive causality running from $\varepsilon_{V}^{2}$ to $R_{t}$ in Hong Kong and Singapore and a significant positive contemporaneous relation between $\varepsilon_{V}^{2}$ and $R_{t}$ in Indonesia. That is, these two relations, as expected, do not exist in most of our sample stock markets.
} 
the causal relation between current return volatility and lagged trading volume, we use the constant correlation bivariate GARCH model, proposed by Bollerslev (1990). For the conditional variances we use the GJR-GARCH specification, proposed by Glosten, Jagannathan, and Runkle (1993). This specification allows the prior positive and negative volatility shocks to have different -i.e., asymmetric impact on the conditional variance. The GJR-GARCH process for stock returns and trading volume is given by: ${ }^{10}$

$$
\begin{aligned}
& \sigma_{R, t}^{2}=\omega_{R}+\sum_{n=1}^{N} \delta_{n, p} \sigma_{R, t-n}^{2}+\sum_{o=1}^{O} \kappa_{R, o}\left(\varepsilon_{R, t-o}\right)^{2}+\lambda_{R} S_{R, t-1}^{-}\left(\varepsilon_{R, t-1}\right)^{2}+\sum_{l=1}^{L} \theta_{R, l} V_{t-l}, \\
& \sigma_{V, t}^{2}=\omega_{V}+\sum_{p=1}^{P} \delta_{V, p} \sigma_{V, t-p}^{2}+\sum_{q=1}^{Q} \kappa_{V, q}\left(\varepsilon_{V, t-q}\right)^{2}+\lambda_{V} S_{V, t-1}^{-}\left(\varepsilon_{V, t-1}\right)^{2}
\end{aligned}
$$

where $\sigma_{R, t}^{2}$ and $\sigma_{V, t}^{2}$ are the conditional variances of stock returns and trading volume at time $t$, respectively, and the dummy variables $S_{R, t-1}^{-1}$ and $S_{V, t-1}^{-1}$ take on a value of one if $\mathcal{E}_{R, t-1}<0$ and if $\varepsilon_{V, t-1}<0$, respectively, and zero otherwise. ${ }^{11}$ It should be noted that we allow for the specification of equations (3) and (4) to have the different ARCH and GARCH effects on stock returns and trading volume. The constant correlation GARCH model imposed the following restriction on the covariance between stock returns and trading volume:

$$
\sigma_{R V, t}=\sigma_{V R, t}=\rho_{R V} \sigma_{R, t} \sigma_{V, t},
$$

where $\rho_{R V}$ represents the correlation coefficient.

The asymmetric effect of negative news is captured by $\lambda_{R}$ and $\lambda_{V}$ in equations (3)

\footnotetext{
10 The theoretical literature provides no clear implications of the role played by the variability of trading activity. Chordia, Swaminathan, and Anshuman (2001) argue that the volatility of trading activity may proxy for liquidity risk. However, their findings do not lend themselves to this explanation in that they find a negative relation between expected stock returns and the second moment of measures of trading activity, such as dollar volume and share turnover.

11 We also estimate our bivariate GJR-GARCH model by adding more lags in the asymmetry terms and find that they are not statistically significant at all in all cases.
} 
and (4), respectively. For example, if $\lambda_{R}>0$, a negative return shock has a larger impact on the conditional variance of stock returns than does a positive return shock of an equal magnitude. Parameter $\lambda_{V}$ in equation (4) can be interpreted analogously.

In addition, to explore the causal relation between return volatility and trading volume, we incorporate lagged volume into equation (3). Therefore, the $\theta_{R, l}$ parameters can be used to test the impact of lagged trading volume on current volatility. For example, if lagged volume affects volatility, the $\theta_{R, l}$ parameters are statistically significant.

\subsection{The log-likelihood function}

To account for the leptokurtosis of the innovations to stock returns and trading volume, as noted from the results of Table 1, we follow Bollerslev (1987) by assuming that the conditional innovations in equations (1) and (2) follow a multivariate Student- $t$ density. The complete model is given by:

$$
\begin{aligned}
& \mathcal{E}_{t}\left|\Omega_{t-1} \equiv\left[\varepsilon_{R, t} \varepsilon_{V, t}\right]^{\prime}\right| \Omega_{t-1} \sim \text { multivariate Student- } t\left(0, H_{t}, s\right), \\
& H_{t}=\left[\begin{array}{cc}
\sigma_{R, t}^{2} & \sigma_{R V, t} \\
\sigma_{V R, t} & \sigma_{V, t}^{2}
\end{array}\right],
\end{aligned}
$$

where $\Omega_{t-1}$ is the information set at time $t-1$ and $s$ is the degree of freedom parameter in equation (6). Under the constant correlation GARCH model, only the whole matrix $H_{t}$ is matrix is time-varying, but the conditional correlations across equations are assumed to be constant. This assumption leads to a major reduction in terms of computational complexity and is commonly utilized in multivariate GARCH models -see Baillie and Bollerslev (1990), Chan, Chan, and Karolyi (1991), Ramchand and Susmel (1998), and Tse and Tusi (2002).

The bivariate GJR-GARCH model is estimated by maximizing the following log-likelihood function: 


$$
\begin{aligned}
L(\Theta)= & \sum_{t=1}^{T}\left[\ln \Gamma\left(\frac{s+n}{2}\right)-\ln \Gamma\left(\frac{s}{2}\right)-\frac{n}{2} \ln [(s-2) \pi]\right] \\
& -\frac{1}{2} \sum_{t=1}^{T}\left[\ln \left|H_{t}\right|+(s+n) \ln \left(1+\frac{\varepsilon_{t}^{\prime} H_{t}^{-1} \varepsilon_{t}}{s-2}\right)\right] \text { for } s>2,
\end{aligned}
$$

where $n$ is the variate number in the model, which in our model is two -i.e., $n=2-$ and $\Theta$ is the parameter vector of the model to be estimated. The statistical inference of the model is generated using the robust standard errors developed by Bollerslev and Wooldridge (1992).

\section{Empirical results}

Table 2 reports the estimation results of the bivariate model for each market. Panels A1 and A2 present the estimation results of the conditional mean equations (1) and (2), Panels B1 and B2 the conditional variance equations (3) and (4), and Panel C the conditional correlation coefficient and shape parameter.

\subsection{Conditional means results}

Table 2 reports the estimation results of the bivariate model for each market. Panels A1 and A2 present the estimation results of the conditional mean equations (1) and (2), respectively. ${ }^{12}$ The $W-B(\gamma)$ and $W-C(\beta)$ statistics are Wald tests used to test the null hypothesis that $\gamma_{R, b}=0$ for all $b$ and that $\beta_{V, c}=0$ for all $c$, respectively. Both test statistics follow a chi-square distribution with degrees of freedom given by the lag structure $B$ and $C$, respectively. The $W-1(\gamma)$ and $W-1(\beta)$ statistics are Wald tests used to test the null hypothesis that $\sum \gamma_{R, b}=0$ and that $\sum \beta_{V, c}=0$, respectively, in order to identify the sign (or net effect) of causality. Both tests follow a chi-square distribution with one degree of freedom.

\footnotetext{
12 To conserve space, we do not report the estimated coefficients and the relevant statistics on autocorrelation variables in the conditional mean equations (1) and (2) in Table 2.
} 
Note that if the lag length on trading volume and on stock returns are equal to one, then the $W-B(\gamma)$ and $W-C(\beta)$ statistics will be identical to the $W-1(\gamma)$ and $W-1(\beta)$ statistics, respectively.

Panel A1 of Table 2 shows that the AIC selected lag structure for own market returns, $A$, is larger than a week for 6 markets; while the selected lag structure for trading volume, $B$, is quite short, only one lag is needed for all markets, except for Taiwan. When we look at Granger causality, the $W-B(\gamma)$ statistic rejects the null hypothesis that trading volume does not Granger-cause stock returns and the $W-1(\gamma)$ statistic rejects the null hypothesis that the sum of the $\gamma_{R, b}$ coefficients is equal to zero at the $5 \%$ level for Taiwan and China, indicating a positive causality from trading volume to stock returns only in these two markets. This implies that investors in Taiwan and China can use trading volume to predict future movements in their stock markets.

Panel A2 of Table 2 shows that the AIC selected lag structure for market returns, $C$, is always smaller than a week, except for China; while the selected lag structure for own trading volume, $D$, is much larger for all markets, with lags between 8 to 16 days. The Granger causality test statistic, $W-C(\gamma)$, strongly rejects the null hypothesis that stock returns do not Granger-cause trading volume at all conventional significance levels for all markets. Moreover, the $W-1(\beta)$ statistic strongly rejects the null hypothesis of zero cumulative effect of lagged market returns on trading volume. These findings suggest a significant positive causality running from stock returns to trading volume in all our sample stock markets. This implies that investors in these markets can infer that the degree of liquidity measured by trading volume will increase after their markets go up. Looking at the results from Panels A1 and A2, we find evidence of bi-directional causality between stock returns and trading volume in Taiwan and China. Relating our results to the findings in Griffin et al. (2007), we tend to find stronger positive causality in developing countries than in developed countries. 
This can be seen from the observation that the cumulative effect of lagged stock returns on trading volume, measured by the sum of the $\beta_{V, c}$ coefficients, tend to be larger for developing markets than for developed markets.

The last row in Panel A2 also reports the impact of lagged squared return residuals on trading volume, measured by $\varphi_{V, e}$. The $W-E(\varphi)$ test statistic rejects the null hypothesis that squared return residuals do not Granger-cause trading volume at the $1 \%$ level for seven markets: Japan, Korea, Singapore, Taiwan, China, Indonesia, and Thailand. Moreover, the sum of the $\varphi_{V, e}$ coefficients is positive and the $W-1(\varphi)$ statistic rejects the null hypothesis that $\sum_{e} \varphi_{V, e}=0$ for the same seven markets. For these seven markets, the results indicate a positive causality running from return volatility to trading volume in these markets. Chordia, Roll, and Subrahmanyam (2008) find that liquidity stimulates arbitrage activity. Thus, our findings suggest that return volatility and past returns may contain useful information for arbitrageurs.

Overall, lagged returns seem to play a bigger role in the dynamics of the mean returns-mean volume relation than lagged trading volume. Lagged returns affect mean trading volume in all markets, while lagged trading volume affects mean returns only in two markets, Taiwan and China.

\subsection{Conditional variances results}

Panels B1 and B2 of Table 2 report the estimation results of the conditional variance equations (3) and (4), respectively. As it is usually found for daily stock returns, the ARCH and GARCH effects are significant in all markets. Interestingly, we found the strong ARCH and GARCH effects in daily trading volume in all markets, but Japan and Thailand, where the GARCH and ARCH effects are not significant, respectively. Consistent with the findings of 
Jacobs and Onochie (1998) and Chen and Daigler (2008), these results indicate that the phenomenon of volatility clustering is observed not only in stock returns but also in trading volume in these Asian stock markets. We observe that the average return volatility persistence -i.e., the sum of the $\delta_{R, n}$ and $\kappa_{R, o}$ parameters- is similar in developed and emerging countries $(0.813$ vs. 0.845$)$; but the average volume volatility persistence - i.e., the sum of the $\delta_{V, p}$ and $\kappa_{R, q}$ parameters- is lower in developed markets than in emerging markets $(0.588$ vs. 0.784$)$. That is, the volatility structure in trading volume is more persistence in emerging countries than in developed countries.

We also report results for the asymmetric effect of negative news. Panels B1 and B2 of Table 2 report the estimates of the $\lambda_{R}$ and $\lambda_{v}$ parameters. Under the asymmetric effect hypothesis, we expect to find the $\lambda_{R}$ and $\lambda_{V}$ parameters to be positive and significant. While the asymmetric effect is positive and significant at the $5 \%$ level for stock returns in all markets, the asymmetric effect is positive and significant at the 5\% level for trading volume in only two markets, Korea and Thailand. That is, across markets, we find strong evidence for an asymmetric effect on stock market volatility. However, for trading volume volatility, we find a significant asymmetric effect only in Korea and Thailand.

Finally, we look at the impact of past trading volume on stock market volatility. This impact is measured by $\theta_{R, l}$. Panel B1 of Table 2 shows that the $\theta_{R, 1}$ and $\theta_{R, 2}$ parameters are positive and statistically significant at the 5\% level for all markets, but China, Indonesia, and Thailand. The overall effect is only positive and significant for the five developed markets: Hong Kong, Japan, Korea, Singapore, and Taiwan, indicating a positive causality running from trading volume to return volatility in these stock markets. Taken together with the results reported in Panel A2 of Table 2, there is a positive bi-directional causality between trading volume and return volatility in four developed markets: Japan, Korea, Singapore, and 
Taiwan, at the 5\% significance level. That is, contrary to the intuition suggested in Griffin et al. (2007), a positive bi-directional causality between return volatility and volume is more likely to occur in developed countries than in developing countries.

\subsection{Correlation Results}

Panel $\mathrm{C}$ of Table 2 reports the estimates of the conditional constant correlation coefficient $\rho_{R V}$ between stock returns and trading volume and the shape parameter $s$ of the multivariate Student- $t$ distribution. The correlation coefficients, $\rho_{R V}$, are statistically significant at the $5 \%$ level, positive and range from 0.080 to 0.429 . On average, we observe a slightly stronger contemporaneous correlation in emerging countries than in developed countries $(0.240$ vs. 0.218$)$. Overall, the positive contemporaneous relation between stock returns and trading volume in all markets is consistent with the implication of the theoretical models of Epps (1975), Copeland (1976), Jennings et al. (1981), and Karpoff (1988).

Finally, the shape parameter $s$ for the degree of freedom of the multivariate Student- $t$ distribution is statistically significant in all markets. The estimated degrees of freedom range from 4.496 to 9.249 , finding thick tails, in particular, for Japan, Singapore, and China. Overall, this finding strongly supports the use of non-normal distributions for these markets.

\subsection{Diagnostic Tests}

Lastly, to check the selected lag structures of our bivariate model, we calculate a battery of Ljung-Box tests to examine the serial correlations of the standardized residuals and their squares. The tests show that none of the Ljung-Box $Q$-statistics are statistically significant at conventional levels for all sample stock markets. As a result, we feel comfortable with the lag structures selected in our estimations for both the mean and the volatility equations. We also 
check for normality on the standardized residuals and find that most of them behave better -i.e., less leptokurtic after using the bivariate GJR-GARCH model.

\subsection{Contemporaneous estimated correlation coefficient between volume and return volatility}

To measure the contemporaneous relation between trading volume and return volatility, we use the conditional variance of stock returns estimated from our bivariate GJR-GARCH model as a measure of return volatility. It should be noted, however, that the conditional variance of stock returns specified in equation (3) is a function of lagged trading volume and that trading volume is highly serially correlated. As such, using the conditional return volatility generated from the specification of equation (3) to measure its contemporaneous relation with trading volume will be upward biased. To avoid this problem, we re-estimate our bivariate GJR-GARCH model by excluding lagged trading volume from equation (3), and the resulting conditional variance of stock returns is used as a measure of return volatility. As mentioned in the literature review section, there is a strong theoretical and empirical support for a positively contemporaneous correlation between volume and return volatility. Moreover, Ghysels et al. (2000) report the positively contemporaneous correlation between volume and return volatility as a stylized fact.

Table 3 reports the estimated contemporaneous correlation coefficients between trading volume and return volatility. The estimated correlation coefficients tend to be small, ranging from -0.125 to 0.264 . On average, there is a higher positive correlation in the emerging markets than in the developed markets (0.083 vs. 0.022). The support for the above mentioned stylized fact is not overwhelming. The expected positive and statistically significant correlation is observed in six out of ten markets: Hong Kong, Korea, Singapore, China, Indonesia, and Thailand. We also observe a negative and statistically significant 
correlation in two developed markets: Japan and Taiwan. ${ }^{13}$

\section{Concluding remarks}

Although the contemporaneous and causal relations between trading volume and stock returns and between trading volume and return volatility have attracted a lot of theoretical and empirical attention in the literature, prior empirical studies do not attempt to investigate simultaneously these relations, mainly relying on one-step estimation procedures. This article takes a first step in this direction by specifying a bivariate GJR-GARCH model. This simultaneous approach not only helps to avoid the misspecification problem but also it is more in line with the implications of the theory models.

We apply our approach to ten Asian stock markets. Our major findings are as follows. First, the contemporaneous relation between stock returns and trading volume and the causal relation between current trading volume and lagged stock returns are statistically significant and robust across all sample stock markets. Overall, lagged returns seem to play a bigger role in the dynamics of the mean returns-mean volume relation than lagged trading volume. Lagged returns affect mean trading volume in all markets, while lagged trading volume affects mean returns only in two markets, Taiwan and China. That is, there exists a positive bi-directional causal relation between stock returns and trading volume in Taiwan and China. Second, there is a positive bi-directional causal relation between trading volume and return volatility in Japan, Korea, Singapore, and Taiwan. Third, we find, as expected, a strong asymmetric effect on return volatility in all sample stock markets and on trading volatility only in Korea and Thailand. Fourth, consistent with the literature, we find a positive

\footnotetext{
13 As a robustness check, we also use squared and absolute stock returns as a measure of return volatility to measure the contemporaneous relation between trading volume and return volatility. These two measures have their appeal because they are a non-parametric or model-free measure and, therefore, help avoid the upward bias problem. Using these two measures, we find that the positive contemporaneous relation turn out to be statistically significant also for the Philippines stock market. The rest of the results are similar to those reported in Table 3 for the other stock markets.
} 
contemporaneous relation between trading volume and return volatility in six out of ten markets: Hong Kong, Korea, Singapore, China, Indonesia, and Thailand. But, we also find a negative contemporaneous correlation between trading volume and return volatility in Japan and Taiwan. Overall, the evidence for a strong positive contemporaneous relation between trading volume and return volatility is not overwhelming.

The comparison of the results of developed and developing markets yields four differences. First, the Asian developed economies have, on average, more stable and less autocorrelated returns and trading volume. Second, the positive causality running from stock returns to trading volume tends to be stronger in developing markets. Third, the positive bi-directional causal relation between trading volume and return volatility occurs only in developed markets. Fourth, the GARCH estimation suggests that the volatility structure in trading volume is more persistence in emerging countries than in developed countries. Fifth, the positive bi-directional causality between trading volume and return volatility is more likely to be found in developed markets than in developing markets. 


\section{References}

Akaike, H. (1974). A new look at the statistical identification model. IEEE Transactions on Automatic Control, 19, 716-723.

Amihud, Y., Mendelson, H., \& Pedersen, L. H. (2005). Liquidity and asset prices. Foundations and Trends in Finance, 1, 269-364.

Baillie, R. T., \& Bollerslev, T. (1990). A multivariate generalized ARCH approach to modeling risk premia in the forward foreign exchange rate markets. Journal of International Money and Finance, 9, 309-324.

Baker, M., \& Wurgler, J. (2002). Market timing and capital structure. Journal of Finance, 57, $1-32$.

Berndt, E. R., Hall, B. H., Hall, R. E., \& Hausman, J. A. (1974). Estimation and Inference in Nonlinear Structural Models. Annals of Economic and Social Measurement, 4, 653-665.

Blume, L., Easley, D., \& O'Hara, M. (1994). Market statistics and technical analysis: The role of volume. Journal of Finance, 49, 153-181.

Bollerslev, T. (1987). A conditional heteroskedastic time series model for speculative prices and rates of return. Review of Economics and Statistics, 69, 542-547.

Bollerslev, T. (1990). Modelling the coherence in short-run nominal exchange rates: A multivariate generalized ARCH model. Review of Economics and Statistics, 72, 498-505.

Bollerslev, T., \& Wooldridge, J. M. (1992). Quasi-maximum likelihood estimation and inference in dynamic models with time-varying covariances. Econometric Reviews, 11, 143-172.

Campbell, J. Y., Grossman, S. J., \& Wang, J. (1993). Trading volume and serial correlation in stock returns. Quarterly Journal of Economics, 108, 905-939.

Chan, K., Chan, K. C., \& Karolyi, A. G. (1991). Intraday volatility in the stock index and stock index futures markets. Review of Financial Studies, 4, 657-684.

Chen, Z., \& Daigler, R. T. (2008). An examination of the complementary volume-volatility information theories. Journal of Futures Markets, 28, 963-992.

Chordia, T., Roll, R., \& Subrahmanyam, A. (2008). Liquidity and market efficiency. Journal of Financial Economics, 87, 249-268.

Chordia, T., \& Swaminathan, B. (2000). Trading volume and cross-autocorrelations in stock returns. Journal of Finance, 55, 913-935.

Chordia, T., Swaminathan, B., \& Anshuman, V. R. (2001). Trading activity and expected stock returns. Journal of Financial Economics, 59, 3-32. 
Clark. P. K. (1973). A subordinated stochastic process with finite variance for speculative prices. Econometrica, 41, 135-155.

Cooper, M. (1999). Filter rules based on price and volume in individual security overreaction. Review of Financial Studies, 12, 901-935.

Copeland, T. E. (1976). A model of asset trading under the assumption of sequential information arrival. Journal of Finance, 31, 1149-1168.

Darrat, A. F., Rahman, S., \& Zhong, M. (2003). Intraday trading volume and return volatility of the DJIA stocks: A note. Journal of Banking and Finance, 27, 2035-2043.

De Long, J.B., Shleifer, A., Summers, L., \& Waldmann, R.J. (1990). Positive feedback investment strategies and destabilizing speculation. Journal of Finance, 45, 379-395.

Dickey, D. A., \& Fuller, W. A. (1979). Distribution of the estimators for autoregressive time series with a unit root. Journal of the American Statistical Association, 74, 427-431.

Edison, H. J., \& Warnock, F. E. (2008). Cross-border listings, capital controls, and equity flows to emerging markets. Journal of International Money and Finance, 27, 1013-1027.

Epps, T. W. (1975). Security price changes and transaction volumes: Theory and evidence. American Economic Review, 65, 586-597.

Epps, T. W., \& Epps, M. L. (1976). The stochastic dependence of security price changes and transaction volumes: Implications for the mixture-of-distributions hypothesis. Econometrica, 44, 305-321.

Gallant, A. R., Rossi, P. E., \& Tauchen, G. (1992). Stock prices and volume. Review of Financial Studies, 5, 199-242.

Gerlach, R., Chen, W. S., Lin, S. Y., \& Huang, M. H. (2006). Asymmetric responses of international stock markets to trading volume. Physica A, 360, 422-444.

Gervais, S., Kaniel, R., \& Mingelgrin, D. H. (2001). The high-volume return premium. Journal of Finance, 56, 877-919.

Gervais, S., \& Odean, T. (2001). Learning to be overconfident. Review of Financial Studies, 14, 1-27.

Ghysels, E., Gourieá, C., \& Jasiak, J. (2000). Causality between returns and traded volumes. Annales d'Economie et d. Statistique, 60, 189-206.

Glosten, L. R., Jagannathan, R., \& Runkle, D. (1993). On the relation between the expected value and the volatility of the nominal excess return on stocks. Journal of Finance, 48, $1779-1801$.

Granger, C. W. J. (1969). Investigating causal relations by econometric models and cross-spectral methods. Econometrica, 37, 424.438. 
Griffin, J. M., Nardari, F., \& Stulz, R. M. (2007). Do investors trade more when stocks have performed well? Evidence from 46 countries. Review of Financial Studies, 20, 905-951.

Harris, L. (1987). Transaction data tests of the mixture of distributions hypothesis. Journal of Financial and Quantitative Analysis, 22, 127-141.

Harris, M., \& Raviv, A. (1993). Differences of opinion make a horse race. Review of Financial Studies, 6, 473-506.

Hiemstra, C., \& Jones, J. D. (1994). Testing for linear and nonlinear Granger causality in the stock price-volume relation. Journal of Finance, 49, 1639-1664.

Jacobs, M., \& Onochie, J. (1998). A bivariate generalized autoregressive conditional heteroscedasticity-in-mean study of the relationship between return variability and trading volume in international futures markets. Journal of Futures Markets, 18, 379-397.

Jain, P. C., \& Joh, G. H. (1988). The dependence between hourly prices and trading volume. Journal of Financial and Quantitative Analysis, 23, 269-283.

Jennings, R. H., Starks, L. T., \& Fellingham, J. (1981). An equilibrium model of asset trading with sequential information arrival. Journal of Finance, 36, 143-161.

Jones, C. M., Kaul, G., \& Lipson, M. L. (1994). Transactions, volume, and volatility. Review of Financial Studies, 7, 631-651.

Kandel, E., \& Pearson, N.D. (1995). Differential interpretation of public signals and trade in speculative markets. Journal of Political Economy, 103, 831-972.

Karpoff, J. M. (1987). The relation between price changes and trading volume: A survey. Journal of Financial and Quantitative Analysis, 22, 109-126.

Karpoff, J. M. (1988). Costly short sales and the correlation of returns with volume. Journal of Financial Research, 11, 173-188.

Kocagil, A. E., \& Shachmurove, Y. (1998). Return-volume dynamics in futures markets. Journal of Futures Markets, 18, 399-426.

Lamoureux, C.G., \& Lastrapes, W.D. (1990). Heteroskedasticity in stock return data: Volume versus GARCH effects. Journal of Finance, 45, 221-229.

Lee, C. M. C., \& Swaminathan, B. (2000). Price momentum and trading volume. Journal of Finance, 55, 2017-2069.

Lo, A. W., \& Wang, J. (2000). Trading volume: Definition, data analysis, and implications of portfolio theory. Review of Financial Studies, 13, 257-300.

Malliaris, A. G., \& Urrutia, J. L. (1998). Volume and price relationships: Hypotheses and testing for agricultural futures. Journal of Futures Markets, 18, 53-72. 
Pagan, A. R. (1984). Econometric issues in the analysis of regressions with generalized regressors. International Economic Review, 25, 221-247.

Pástor, L., \& Veronesi, P. (2005). Rational IPO waves. Journal of Finance, 60, 1713-1757.

Phillip, P. C. B., \& Perron, P. (1988). Testing for a unit root in time series regression. Biometrica, 75, 335-346.

Ramchand, L., \& Susmel, R. (1998). Cross correlations across major international markets. Journal of Empirical Finance, 5, 397-416.

Richards, A. (2005). Big fish in small ponds: The trading behavior and price impact of foreign investors in Asian emerging equity markets. Journal of Financial and Quantitative Analysis, 40, 1-27.

Richardson, G., Sefcik, S. E., \& Thompson, R. (1986). A test of dividend irrelevance using volume reaction to a change in dividend policy. Journal of Financial Economics, 17, 313-333.

Sentana, E., \& Wadhwani, S. (1992). Feedback traders and stock return autocorrelation: Evidence from a century of daily data. Economic Journal, 102, 415-425.

Shalen, C.T. (1993). Volume, volatility, and the dispersion of beliefs. Review of Financial Studies, 6, 405-434.

Shefrin, H., \& Statman, M. (1985). The disposition to sell winners too early and ride losers too long: Theory and evidence. Journal of Finance, 40, 777-791.

Smirlock, M., \& Starks, L. (1985). A further examination of stock price changes and transaction volume. Journal of Financial Research, 8, 217-225.

Smirlock, M., \& Starks, L. (1988). An empirical analysis of the stock price-volume relationship. Journal of Banking and Finance, 12, 31-41.

Tauchen, G. E., \& Pitts, M. (1983). The price variability-volume relationship on speculative markets. Econometrica, 51, 485-506.

Tse, Y.K., \& Tsui, K. C. (2002). A multivariate generalized autoregressive conditional heteroscedasticity model with time-varying correlations. Journal of Business and Economic Statistics, 20, 351-362.

Wang, J. (1994). A model of competitive stock trading volume. Journal of Political Economy, $102,127-168$. 


\section{Table 1}

\section{Summary Statistics}

The sample includes ten Asian stock markets and covers the period from January 1, 1998 to December 31, 2007. Panels A and B report the summary statistics on stock returns and detrended trading volume for each sample stock market. The null hypotheses for the skewness and excess kurtosis coefficients are that they are equal to zero. The $D$-statistic denotes the Kolmogorov-Smirnov test for normality. $\rho_{1}$ refers to the first-order autocorrelation. $S_{5}$ refers to the sum of the first 5 autocorrelations. ARCH(10) denotes the chi-square statistic of the Lagrange Multiplier (LM) test for autoregressive conditional heteroskedasticity effects with 10 lags.

\begin{tabular}{|c|c|c|c|c|c|c|c|c|c|c|}
\hline \multicolumn{11}{|c|}{ Panel A: Stock Returns } \\
\hline \multirow[b]{2}{*}{ Country } & \multicolumn{5}{|c|}{ Developed Markets } & \multicolumn{5}{|c|}{ Developing Markets } \\
\hline & Hong Kong & Japan & Korea & Singapore & Taiwan & China & Indonesia & Malaysia & Philippines & Thailand \\
\hline Observations & 2,464 & 2,459 & 2,460 & 2,492 & 2,459 & 2,408 & 2,435 & 2,414 & 2,440 & 2,441 \\
\hline Sample mean $(\%)$ & 0.039 & 0.010 & 0.064 & 0.033 & 0.002 & 0.061 & 0.078 & 0.038 & 0.027 & 0.035 \\
\hline Standard deviation (\%) & 1.594 & 1.256 & 2.080 & 1.423 & 1.593 & 1.512 & 1.730 & 1.614 & 1.530 & 1.743 \\
\hline Return-to-volatility & 0.024 & 0.008 & 0.031 & 0.023 & 0.001 & 0.040 & 0.045 & 0.024 & 0.018 & 0.020 \\
\hline Skewness & $0.149^{* * *}$ & $-0.179 * * *$ & $-0.109 * *$ & $-0.251 * * *$ & -0.066 & 0.021 & -0.004 & $1.580 * * *$ & $0.888^{* * *}$ & $0.229 * * *$ \\
\hline Excess kurtosis & $5.400 * * *$ & $1.659 * * *$ & $3.010^{* * *}$ & $11.589 * * *$ & $2.510 * * *$ & $4.738 * * *$ & $6.930 * * *$ & $69.410 * * *$ & $12.460 * * *$ & $7.688 * * *$ \\
\hline$D$-statistic & $0.066^{* * *}$ & $0.044 * * *$ & $0.071 * * *$ & $0.070 * * *$ & $0.059 * * *$ & $0.064 * * *$ & $0.077 * * *$ & $0.142 * * *$ & $0.069^{* * *}$ & $0.071 * * *$ \\
\hline$\rho_{1}$ & 0.050 & 0.071 & 0.068 & 0.117 & 0.043 & 0.018 & 0.139 & 0.034 & 0.153 & 0.080 \\
\hline$S_{5}$ & -0.018 & -0.056 & -0.050 & 0.142 & 0.089 & 0.078 & 0.134 & 0.004 & 0.139 & 0.123 \\
\hline $\mathrm{ARCH}(10)$ & $211.293 * * *$ & $137.679 * * *$ & $166.600 * * *$ & $116.797 * * *$ & $223.728 * * *$ & $120.256^{* * *}$ & $200.726 * * *$ & $340.858 * * *$ & $52.603 * * *$ & $324.062 * * *$ \\
\hline \multicolumn{11}{|c|}{ Panel B: Detrended Trading Volume } \\
\hline & \multicolumn{5}{|c|}{ Developed Markets } & \multicolumn{5}{|c|}{ Developing Markets } \\
\hline Country & Hong Kong & Japan & Korea & Singapore & Taiwan & China & Indonesia & Malaysia & Philippines & Thailand \\
\hline Observations & 2,465 & 2,460 & 2,461 & 2,493 & 2,460 & 2,409 & 2,436 & 2,415 & 2,441 & 2,442 \\
\hline Sample mean & 0.000 & 0.000 & 0.000 & 0.000 & 0.000 & 0.000 & 0.000 & 0.000 & 0.000 & 0.000 \\
\hline Standard deviation & 0.464 & 0.314 & 0.437 & 0.689 & 0.388 & 0.553 & 0.640 & 0.622 & 1.037 & 0.641 \\
\hline Skewness & $0.113^{* *}$ & $-1.381 * * *$ & $-0.811 * * *$ & $-0.413^{* * *}$ & $0.145 * * *$ & $0.341 * * *$ & 0.065 & $0.301 * * *$ & $0.280 * * *$ & 0.031 \\
\hline Excess kurtosis & $1.213^{* * *}$ & $13.228 * * *$ & $8.220 * * *$ & $3.110 * * *$ & -0.002 & $-0.507 * * *$ & $0.681 * * *$ & $1.149 * * *$ & $0.769 * * *$ & -0.032 \\
\hline$D$-statistic & 0.013 & $0.078 * * *$ & $0.031 * * *$ & $0.085 * * *$ & $0.029 * * *$ & $0.054 * * *$ & $0.020 * *$ & $0.032 * * *$ & $0.028 * * *$ & $0.025 * * *$ \\
\hline$\rho_{1}$ & 0.703 & 0.581 & 0.795 & 0.750 & 0.839 & 0.895 & 0.704 & 0.847 & 0.780 & 0.854 \\
\hline$S_{5}$ & 2.955 & 2.327 & 3.587 & 3.069 & 3.702 & 4.001 & 2.963 & 3.700 & 3.590 & 3.644 \\
\hline $\mathrm{ARCH}(10)$ & $73.844 * * *$ & $133.892 * * *$ & $117.204 * * *$ & $243.607 * * *$ & $204.896 * * *$ & $90.118 * * *$ & $96.854 * * *$ & $160.308^{* * *}$ & $63.599 * * *$ & $64.760 * * *$ \\
\hline
\end{tabular}

1. $* * *, * *$ and $*$ denote significant at the $1 \%, 5 \%, 10 \%$ levels, respectively.

2. The critical values and statistical significance levels for the Kolmogorov-Smirnov $D$-statistic with 2300 observations are: 0.021 at $1 \%, 0.018$ at $5 \%$, and 0.016 at $10 \%$. 
Table 2

\section{Estimates of the Bivariate GJR-GARCH Model}

The following bivariate GJR-GARCH model is estimated to investigate the contemporaneous and causal relations between stock returns and trading volume and the causal relation between trading volume and return volatility over the period from January 1, 1998 to December 31, 2007 for each sample stock market:

$$
\begin{aligned}
& R_{t}=\alpha_{R, 0}+\sum_{a=1}^{A} \beta_{R, a} R_{t-a}+\sum_{b=1}^{B} \gamma_{R, b} V_{t-b}+\varepsilon_{R, t}, \\
& V_{t}=\alpha_{V, 0}+\sum_{c=1}^{c} \beta_{V, c} R_{t-c}+\sum_{d=1}^{D} \gamma_{V, d} V_{t-d}+\sum_{e=1}^{E} \varphi_{V, e} \varepsilon_{R, t-e}^{2}+\varepsilon_{V, t}, \\
& \sigma_{R, t}^{2}=\omega_{R}+\sum_{n=1}^{N} \delta_{R, n} \sigma_{R, t-n}^{2}+\sum_{o=1}^{o} \kappa_{R, o}\left(\varepsilon_{R, t-o}\right)^{2}+\lambda_{R} S_{R, t-1}^{-}\left(\varepsilon_{R, t-1}\right)^{2}+\sum_{l=1}^{L} \theta_{R, l} V_{t-l}, \\
& \sigma_{V, t}^{2}=\omega_{V}+\sum_{p=1}^{P} \delta_{V, p} \sigma_{V, t-p}^{2}+\sum_{q=1}^{Q} \kappa_{V, q}\left(\varepsilon_{V, t-q}\right)^{2}+\lambda_{V} S_{V, t-1}^{-}\left(\varepsilon_{V, t-1}\right)^{2},
\end{aligned}
$$

where $R_{t}$ is the stock return at time $t$ and $V_{t}$ is the trading volume at time $t$. The number of lags in equations (1) and (2) is chosen using the Akaike Information Criterion (AIC) (Akaike (1974)). Maximum likelihood estimates of the parameters are obtained using the Berndt-Hall-Hall-Hausman (BHHH) (1974) optimization algorithm to maximize the log-likelihood function. The $W-B(\gamma)$ and $W-C(\beta)$ statistics of the Wald tests, which follow a chi-square distribution with $B$ and $C$ degrees of freedom, respectively, are used to test the null hypothesis that $\gamma_{R, b}=0$ for all $b$ and that $\beta_{V, c}=0$ for all $c$, respectively. The $W$-1 statistic of the Wald test, which follows a chi-square

\begin{tabular}{|c|c|c|c|c|c|c|c|c|c|c|}
\hline \multicolumn{11}{|c|}{ Panel A1: Conditional Mean Equation of Stock Returns } \\
\hline \multirow[b]{2}{*}{ Country } & \multicolumn{5}{|c|}{ Developed Markets } & \multicolumn{5}{|c|}{ Developing Markets } \\
\hline & Hong Kong & Japan & Korea & Singapore & Taiwan & China & Indonesia & Malaysia & Philippines & Thailand \\
\hline$\overline{\text { Lag length } A}$ & 5 & 6 & 3 & 13 & 3 & 6 & 10 & 9 & 5 & 10 \\
\hline Lag length $B$ & 1 & 1 & 1 & 1 & 2 & 1 & 1 & 1 & 1 & 1 \\
\hline$W-B(\gamma)$ & $\begin{array}{l}0.001 \\
{[0.970]}\end{array}$ & $\begin{array}{l}1.887 \\
{[0.170]}\end{array}$ & $\begin{array}{l}0.002 \\
{[0.965]}\end{array}$ & $\begin{array}{l}1.012 \\
{[0.314]}\end{array}$ & $\begin{array}{l}18.349 * * * \\
{[0.000]}\end{array}$ & $\begin{array}{l}18.330 * * * \\
{[0.000]}\end{array}$ & $\begin{array}{l}2.280 \\
{[0.258]}\end{array}$ & $\begin{array}{l}0.002 \\
{[0.962]}\end{array}$ & $\begin{array}{l}0.022 \\
{[0.883]}\end{array}$ & $\begin{array}{l}0.001 \\
{[0.972]}\end{array}$ \\
\hline
\end{tabular}
distribution with 1 degree of freedom, is used to test the null hypothesis that $\sum_{b} \gamma_{R, b}=0$ and that $\sum_{c} \beta_{v, c}=0$. The $p$-values of the Wald tests are reported in brackets beneath the test statistics. $\rho_{R V}$ is the conditional correlation coefficient and $s$ is the degree-of-freedom shape parameter of the multivariate Student- $t$ distribution. The Bollerslev and Wooldridge (1992) robust standard errors are shown in parentheses beneath the estimated coefficients. 


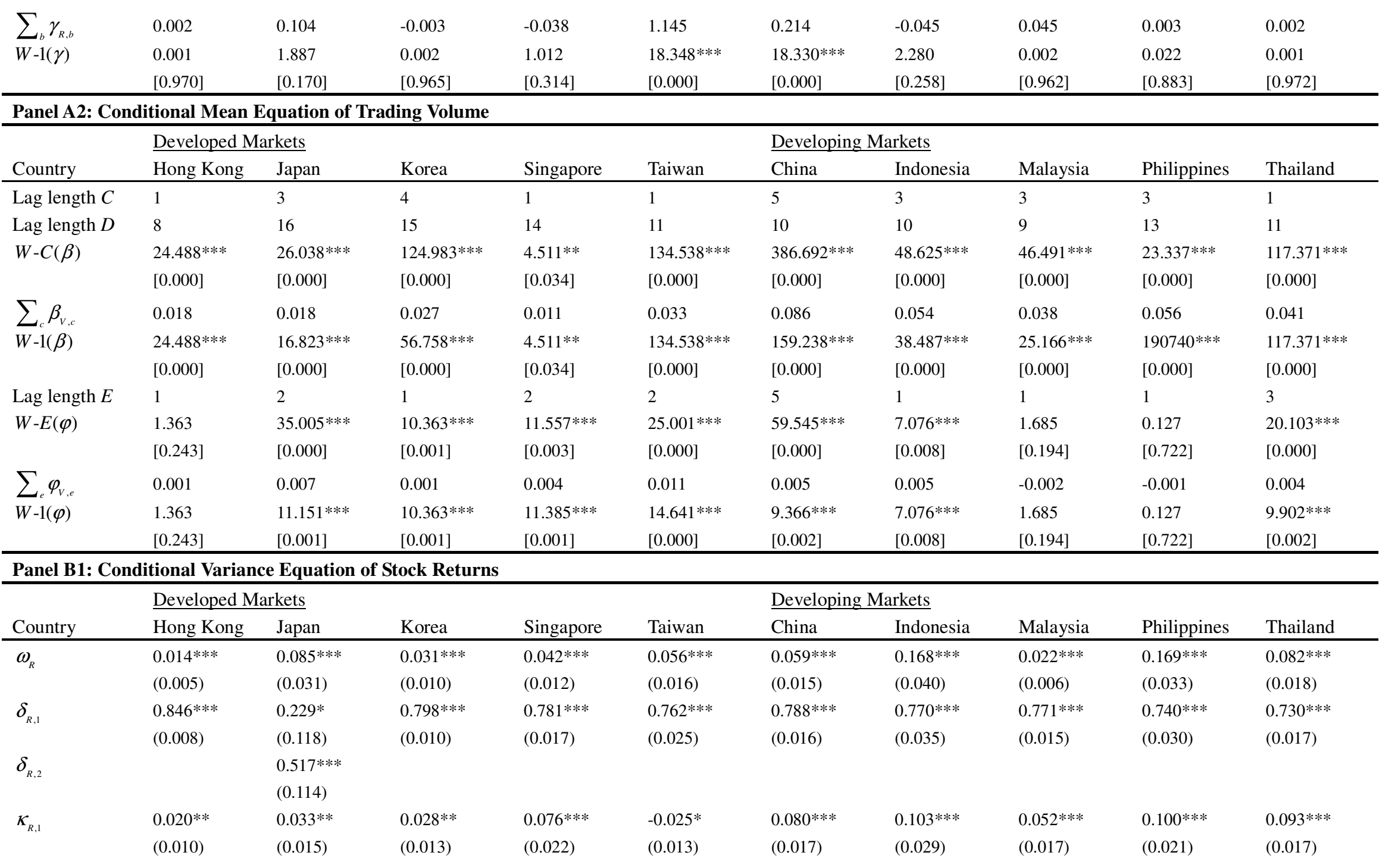




\begin{tabular}{|c|c|c|c|c|c|c|c|c|c|c|}
\hline$\kappa_{R, 2}$ & & & $\begin{array}{l}0.086^{* * * *} \\
(0.020)\end{array}$ & & $\begin{array}{l}0.068 * * * \\
(0.022)\end{array}$ & & $\begin{array}{l}-0.083 * * * \\
(0.038)\end{array}$ & & & \\
\hline$\lambda_{R}$ & $\begin{array}{l}0.056^{* * *} \\
(0.013)\end{array}$ & $\begin{array}{l}0.180 * * * \\
(0.036)\end{array}$ & $\begin{array}{l}0.048 * * * \\
(0.013)\end{array}$ & $\begin{array}{l}0.083 * * * \\
(0.029)\end{array}$ & $\begin{array}{l}0.106 * * * \\
(0.020)\end{array}$ & $\begin{array}{l}0.064 * * * \\
(0.024)\end{array}$ & $\begin{array}{l}0.136 * * * \\
(0.036)\end{array}$ & $\begin{array}{l}0.112 * * * \\
(0.024)\end{array}$ & $\begin{array}{l}0.081 * * * \\
(0.030)\end{array}$ & $\begin{array}{l}0.079 * * * \\
(0.025)\end{array}$ \\
\hline$\theta_{R, 1}$ & $\begin{array}{l}0.016^{* *} \\
(0.008)\end{array}$ & $\begin{array}{l}0.135 * * \\
(0.062)\end{array}$ & $\begin{array}{l}0.072 * * \\
(0.033)\end{array}$ & $\begin{array}{l}0.043 * * \\
(0.017)\end{array}$ & $\begin{array}{l}0.063 * * \\
(0.025)\end{array}$ & $\begin{array}{l}0.003 \\
(0.021)\end{array}$ & $\begin{array}{l}0.039 * \\
(0.022)\end{array}$ & $\begin{array}{l}0.206^{* * *} \\
(0.043)\end{array}$ & $\begin{array}{l}0.132 * * * \\
(0.057)\end{array}$ & $\begin{array}{l}0.010 \\
(0.017)\end{array}$ \\
\hline$\theta_{R, 2}$ & & & $\begin{array}{l}0.058 * * * \\
(0.014) \\
\end{array}$ & & & & & $\begin{array}{l}-0.194 * * * \\
(0.042)\end{array}$ & $\begin{array}{l}-0.118 * * \\
(0.057)\end{array}$ & \\
\hline \multicolumn{11}{|c|}{ Panel B2: Conditional Variance Equation of Trading Volume } \\
\hline \multirow[b]{2}{*}{ Country } & \multicolumn{5}{|c|}{$\underline{\text { Developed Markets }}$} & \multicolumn{3}{|c|}{ Developing Markets } & & \\
\hline & Hong Kong & Japan & Korea & Singapore & Taiwan & China & Indonesia & Malaysia & Philippines & Thailand \\
\hline$\omega_{V}$ & $\begin{array}{l}0.017 * * \\
(0.007)\end{array}$ & $\begin{array}{l}0.022 * * * \\
(0.002)\end{array}$ & $\begin{array}{l}0.008 * * * \\
(0.001)\end{array}$ & $\begin{array}{l}0.041 * * * \\
(0.006)\end{array}$ & $\begin{array}{l}0.001 * * \\
(0.000)\end{array}$ & $\begin{array}{l}0.001 * * * \\
(0.000)\end{array}$ & $\begin{array}{l}0.001 \\
(0.001)\end{array}$ & $\begin{array}{l}0.034 * * * \\
(0.006)\end{array}$ & $\begin{array}{l}0.098^{* * *} \\
(0.027)\end{array}$ & $\begin{array}{l}0.002 * * \\
(0.001)\end{array}$ \\
\hline$\delta_{V, 1}$ & $\begin{array}{l}0.752 * * * \\
(0.091)\end{array}$ & $\begin{array}{l}0.107 \\
(0.066)\end{array}$ & $\begin{array}{l}0.228 * * * \\
(0.024)\end{array}$ & $\begin{array}{l}0.435 * * * \\
(0.058)\end{array}$ & $\begin{array}{l}0.813 * * * \\
(0.017)\end{array}$ & $\begin{array}{l}0.861 * * * \\
(0.010)\end{array}$ & $\begin{array}{l}0.909 * * * \\
(0.007)\end{array}$ & $\begin{array}{l}0.403 * * * \\
(0.088)\end{array}$ & $\begin{array}{l}0.607 * * * \\
(0.091)\end{array}$ & $\begin{array}{l}0.831 * * * \\
(0.011)\end{array}$ \\
\hline \multicolumn{11}{|l|}{$\delta_{V, 2}$} \\
\hline$\kappa_{V, 1}$ & $\begin{array}{l}0.038 * * \\
(0.016)\end{array}$ & $\begin{array}{l}0.238 * * * \\
(0.055)\end{array}$ & $\begin{array}{l}0.054 * * \\
(0.023)\end{array}$ & $\begin{array}{l}0.223 * * * \\
(0.045)\end{array}$ & $\begin{array}{l}0.067 * * * \\
(0.022)\end{array}$ & $\begin{array}{l}0.027 * * * \\
(0.008)\end{array}$ & $\begin{array}{l}0.074 * * * \\
(0.024)\end{array}$ & $\begin{array}{l}0.195 * * * \\
(0.045)\end{array}$ & $\begin{array}{l}0.107 * * * \\
(0.027)\end{array}$ & $\begin{array}{l}0.006 \\
(0.008)\end{array}$ \\
\hline$\kappa_{V, 2}$ & & & & $\begin{array}{l}0.047 * * * \\
(0.015)\end{array}$ & $\begin{array}{l}-0.060 * * \\
(0.026)\end{array}$ & & $\begin{array}{l}-0.099 * * * \\
(0.033)\end{array}$ & & & \\
\hline$\lambda_{V}$ & $\begin{array}{l}0.045 \\
(0.032)\end{array}$ & $\begin{array}{l}-0.040 \\
(0.068) \\
\end{array}$ & $\begin{array}{l}0.103 * * \\
(0.043)\end{array}$ & $\begin{array}{l}0.083 \\
(0.066)\end{array}$ & $\begin{array}{l}0.026 \\
(0.019) \\
\end{array}$ & $\begin{array}{l}0.038^{*} \\
(0.021) \\
\end{array}$ & $\begin{array}{l}0.015^{*} \\
(0.008) \\
\end{array}$ & $\begin{array}{l}-0.031 \\
(0.058) \\
\end{array}$ & $\begin{array}{l}-0.040 \\
(0.045)\end{array}$ & $\begin{array}{l}0.058^{* * *} \\
(0.018)\end{array}$ \\
\hline \multicolumn{11}{|c|}{ Panel C: Conditional Correlation Coefficient and Shape Parameter } \\
\hline \multirow[b]{2}{*}{ Country } & \multicolumn{5}{|c|}{$\underline{\text { Developed Markets }}$} & \multicolumn{3}{|c|}{$\underline{\text { Developing Markets }}$} & & \\
\hline & Hong Kong & Japan & Korea & Singapore & Taiwan & China & Indonesia & Malaysia & Philippines & Thailand \\
\hline$\rho_{R V}$ & $\begin{array}{l}0.079 * * * \\
(0.024)\end{array}$ & $\begin{array}{l}0.169 * * * \\
(0.025)\end{array}$ & $\begin{array}{l}0.228 * * * \\
(0.024)\end{array}$ & $\begin{array}{l}0.184 * * * \\
(0.027)\end{array}$ & $\begin{array}{l}0.429 * * * \\
(0.020)\end{array}$ & $\begin{array}{l}0.273 * * * \\
(0.023)\end{array}$ & $\begin{array}{l}0.224 * * * \\
(0.024)\end{array}$ & $\begin{array}{l}0.288 * * * \\
(0.024)\end{array}$ & $\begin{array}{l}0.080 * * * \\
(0.025)\end{array}$ & $\begin{array}{l}0.334 * * * \\
(0.021)\end{array}$ \\
\hline$s$ & $\begin{array}{l}6.978 * * * \\
(0.599)\end{array}$ & $\begin{array}{l}4.496 * * * \\
(20.005)\end{array}$ & $\begin{array}{l}6.389 * * * \\
(0.316)\end{array}$ & $\begin{array}{l}4.973 * * * \\
(0.332)\end{array}$ & $\begin{array}{l}8.563 * * * \\
(0.964)\end{array}$ & $\begin{array}{l}4.954 * * * \\
(0.354)\end{array}$ & $\begin{array}{l}8.492 * * * \\
(0.922)\end{array}$ & $\begin{array}{l}5.707 * * * \\
(0.368)\end{array}$ & $\begin{array}{l}6.664 * * * \\
(0.481)\end{array}$ & $\begin{array}{l}9.249 * * * \\
(0.638)\end{array}$ \\
\hline
\end{tabular}


Table 3

Contemporaneous Correlation between Trading Volume and Return Volatility

The table reports the contemporaneous correlation coefficients between trading volume and return volatility and the corresponding Z-statistics based on the large sample for 10 Asian stock markets for the sample period from January 1, 1998 to December 31, 2007. The conditional variance of stock returns is estimated from the bivariate GJR-GARCH model of equations (1) to (4) in which lagged trading volume is excluded from the conditional variance equation of stock returns.

\begin{tabular}{|c|c|c|c|c|c|c|c|c|c|c|}
\hline \multirow[b]{2}{*}{ Country } & \multicolumn{5}{|c|}{ Developed Markets } & \multicolumn{5}{|c|}{$\underline{\text { Developing Markets }}$} \\
\hline & Hong Kong & Japan & Korea & Singapore & Taiwan & China & Indonesia & Malaysia & Philippines & Thailand \\
\hline Correlation coefficient & 0.184 & -0.131 & 0.116 & 0.067 & -0.125 & 0.264 & 0.068 & -0.024 & 0.008 & 0.101 \\
\hline$Z$-statistic & $8.962 * * *$ & $-5.441 * * *$ & $5.589 * * *$ & $2.997 * * *$ & $-5.937 * * *$ & $12.840 * * *$ & $3.199 * * *$ & -1.096 & 0.406 & $4.882 * * *$ \\
\hline
\end{tabular}

